\title{
Anterior Chamber Dislocation of Ozurdex Implant: A Case Report
}

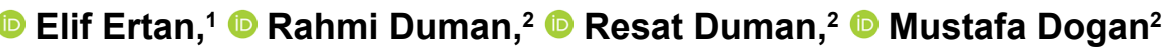 \\ ${ }^{1}$ Department of Ophthalmology, Siirt Kurtalan State Hospital, Siirt, Turkey \\ ${ }^{2}$ Department of Ophthalmology, Afyon Kocatepe University, Afyonkarahisar, Turkey
}

\begin{abstract}
Anterior chamber dislocation of an Ozurdex (Allergan plc, Dublin, Ireland) implant from the vitreous cavity is unusual. The risk factors for dexamethasone implant migration into the anterior chamber include a defective posterior lens capsule, aphakia, and a prior history of pars plana vitrectomy. Presently described is a case of corneal toxicity occurring after the migration of a dexamethasone implant into the anterior chamber.
\end{abstract}

Keywords: Anterior migration, corneal edema, cystoid macular edema, dexamethasone implant.

\section{Introduction}

Implantation of dexamethasone (DEX) (Ozurdex; Allergan, Inc., Dublin, Ireland) is an approved treatment for macular edema due to branch or central retinal vein occlusion, diabetic macular edema, or noninfectious uveitis affecting the posterior segment (I). Ozurdex is associated with ocular side effects, such as conjunctival hemorrhage, endopthalmitis, cataracts, glaucoma, and retinal detachment (2). There may also be complications due to the implant itself, such as desegmentation (fracture) of the implant, accidental injection of Ozurdex into the crystalline lens, and migration of the Ozurdex implant into the anterior chamber (3-5). This report describes a case of corneal toxicity occurring after migration of a DEX implant into the anterior chamber.

\section{Case Report}

The patient was a 78-year-old woman with diabetic macular edema (DME), a best-corrected visual acuity (BCVA) of 20/200, intraocular pressure (IOP) measured at $18 \mathrm{mmHg}$, and a central macular thickness (CMT) of 450 mikron in the left eye. The patient had undergone a complicated cataract surgery 2 years earlier with a scleral-fixated posterior chamber lens implant and a defective iris. She had previously received 5 intravitreal injections of ranibizumab and I DEX implant (Ozurdex) in the left eye for the DME. The implant was injected via the pars plana route $3.5 \mathrm{~mm}$ from the limbus following topical anesthesia with proparacaine. An uneventful intravitreal DEX implant injection was performed. However, 3 weeks after the injection, the patient presented at the clinic complaining of pain and vision loss in her left eye ongoing for a week. The intraocular pressure measured during the first visit was $18 \mathrm{mmHg}$. An anterior segment examination revealed corneal edema and the rod implant adhered to the corneal endothelium (Fig. I). The implant was surgically removed from the anterior chamber 24 hours later. After the removal of the DEX implant, the patient was administered an eye drop formula consisting of $5 \%$ hypertonic solution to reduce the edema in the cornea, 5 times per day for 6 months. Six months after the DEX injection, BCVA was measured at 20/400, and the corneal edema had not resolved. The patient is awaiting corneal transplantation. 


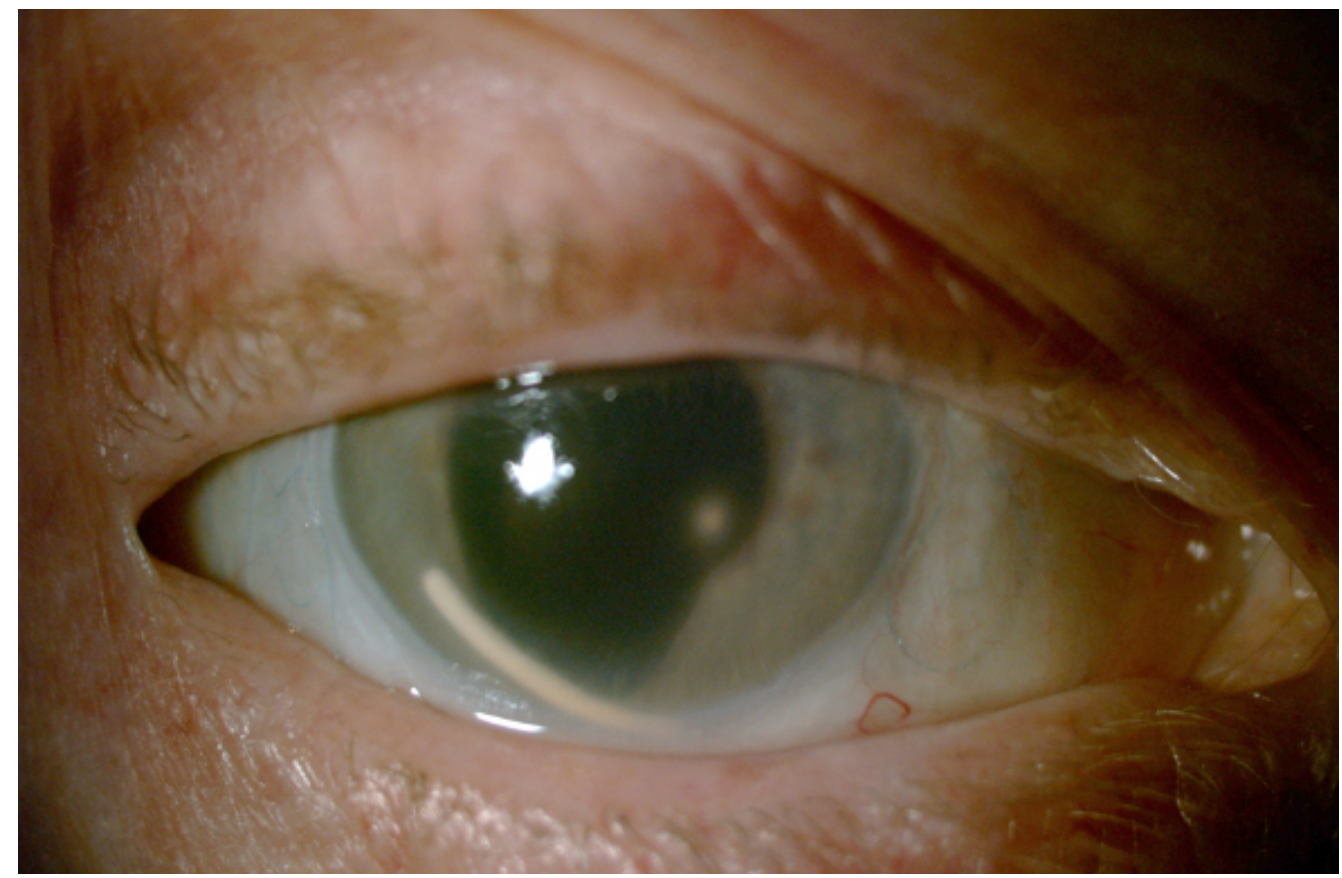

Figure I. Slit-lamp biomicroscopy showing the dexamethasone implant dislocated in the anterior Chamber with diffuse corneal edema.

\section{Discussion}

In the GENEVA (Global Evaluation of implantable dexamethasone in retinal vein occlusion with macular edema) phase III clinical trial evaluating the DEX implant for treatment of macular edema secondary to retinal vein occlusion in 1256 patients and in the Ozurdex MEAD Study group phase III trial examining the efficacy of a DEX implant in 1048 patients with diabetic macular edema (DME), no cases of the steroid implant migrating into the anterior chamber occurred. However, in both studies, eyes with aphakia and those with a history of pars plana vitrectomy (PPV) were excluded (6, 7). The risk factors for DEX implant migration into the anterior chamber include a defective posterior lens capsule, aphakia, and a prior history of PPV. Anterior migration of a DEX implant in pseudophakic and aphakic eyes with corneal decompensation and increased IOP has been previously reported. Khurana et al. (5) reported 15 cases including eyes with aphakia and pseudophakia with anterior chamber, iris-fixated, scleral-fixated, and intracapsular posterior chamber intraocular lens. Pardo et al. (8) reported a case of anterior dislocation of the DEX implant in a pseudophakic patient who had an iris-claw intraocular lens. Bansal et al. (9) reported 3 cases of anterior dislocation of the DEX implant in aphakic vitrectomized eyes. The authors reported that the implant was repositioned in the vitreous cavity in 2 cases. However the third case required surgical removal with postsurgery persistence of corneal edema.

Corneal edema is the most serious complication of DEX implant migration in the anterior chamber. Corneal endothelial toxicity may be due to mechanical trauma from the implant as well as chemical toxicity. In the setting of migration of the DEX implant into the anterior chamber, there are a few management strategies. The surgical management strategies include the repositioning of the implant into the vitreous, Neodymium-doped yttrium aluminum garnet ( $\mathrm{Nd}$ YAG) laser to fragment the implant, aspiration of the disintegrated implant, and forceps are used to remove the implant (5). Pacella et al. (I0) also reported a case of an effective repositioning of a DEX implant through mobilization and subsequent balanced saline solution injection in the anterior chamber.

We did not elect to reposition the DEX; we preferred complete removal because the patient had a defective iris, which could cause recurrence of anterior chamber migration. If the implant migrates into the anterior chamber and there is corneal edema, we recommend immediate removal of the DEX implant.

\section{Disclosures}

Informed consent: Written informed consent was obtained from the patient for the publication of the case report and the accompanying images.

Peer-review: Externally peer-reviewed.

Conflict of Interest: None declared.

Authorship Contributions: Involved in design and conduct of the study (EE); preparation and review of the study (EE, RD, RD, $M D$ ); data collection (EE, RD, RD, MD). 


\section{References}

I. London NJ, Chiang A, Haller JA. The dexamethasone drug delivery system: indications and evidence. Adv Ther 20I I;28:35I-66.

2. Schmitz K, Maier M, Clemens CR, Höhn F, Wachtlin J, Lehmann F, et al; German Retinal Vein Occlusion Group. Reliability and safety of intravitreal Ozurdex injections. The ZERO study [Article in German]. Ophthalmologe 2014; I I I:44-52. [CrossRef]

3. Agrawal R, Fernandez-Sanz G, Bala S, Addison PK. Desegmentation of Ozurdex implant in vitreous cavity: report of two cases. Br J Ophthalmol 2014;98:96I-3. [CrossRef]

4. Coca-Robinot J, Casco-Silva B, Armadá-Maresca F, GarcíaMartínez J. Accidental injections of dexamethasone intravitreal implant (Ozurdex) into the crystalline lens. Eur J Ophthalmol 2014;24:633-6. [CrossRef]

5. Khurana RN, Appa SN, McCannel CA, Elman MJ, Wittenberg SE, Parks DJ, et al. Dexamethasone implant anterior chamber migration: risk factors, complications, and management strategies. Ophthalmology 2014;121:67-71. [CrossRef]

6. Haller JA, Bandello F, Belfort R Jr, Blumenkranz MS, Gillies M,
Heier J, et al; Ozurdex GENEVA Study Group. Dexamethasone intravitreal implant in patients with macular edema related to branch or central retinal vein occlusion twelve-month study results. Ophthalmology 20II; I 18:2453-60. [CrossRef]

7. Boyer DS, Yoon YH, Belfort R Jr, Bandello F, Maturi RK, Augustin AJ, et al; Ozurdex MEAD Study Group. Three-year, randomized, sham-controlled trial of dexamethasone intravitreal implant in patients with diabetic macular edema. Ophthalmology 2014;121:1904-14. [CrossRef]

8. Pardo-López D, Francés-Muñoz E, Gallego-Pinazo R, Díaz-Llopis $M$. Anterior chamber migration of dexametasone intravitreal implant (Ozurdex®). Graefes Arch Clin Exp Ophthalmol 20I2;250:I703-4. [CrossRef]

9. Bansal R, Bansal P, Kulkarni P, Gupta V, Sharma A, Gupta A. Wandering Ozurdex $(\circledR)$ implant. J Ophthalmic Inflamm Infect 2012;2:I-5. [CrossRef]

10. Pacella F, Agostinelli E, Carlesimo SC, Nebbioso M, Secondi R, Forastiere $\mathrm{M}$, et al. Management of anterior chamber dislocation of a dexamethasone intravitreal implant: a case report. J Med Case Rep 2016;10:282. [CrossRef] 